\title{
Molecular Profiling of Vascular Remodeling in Chronic Pulmonary Disease
}

Lavinia Neubert, ${ }^{\star \dagger}$ Paul Borchert, ${ }^{* \dagger}$ Helge Stark, ${ }^{* \dagger}$ Anne Hoefer, ${ }^{* \dagger}$ Jens Vogel-Claussen, ${ }^{\dagger \ddagger}$ Gregor Warnecke, ${ }^{\dagger \S}$ Holger Eubel, Patrick Kuenzler, ${ }^{\top}$ Hans-Heinrich Kreipe, ${ }^{*}$ Marius M. Hoeper, ${ }^{\dagger \mid}$ Mark Kuehnel, ${ }^{\star \dagger}$ and Danny Jonigk ${ }^{* \dagger}$

From the Institute of Pathology, * the Institute for Radiology, ${ }^{\ddagger}$ the Department of Cardiothoracic, Transplantation, and Vascular Surgery, ${ }^{\S}$ and the Clinic for Pneumology, "Hannover Medical School; the German Center for Lung Research (DZL), ${ }^{\dagger}$ Biomedical Research in End-stage and Obstructive Lung Disease Hannover (BREATH); and the Institute of Plant Genetics, "Leibniz University Hanover, Hannover, Germany

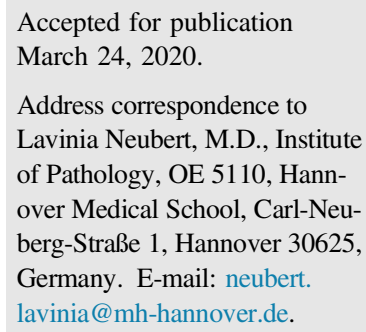

Address correspondence to Lavinia Neubert, M.D., Institute of Pathology, OE 5110, Hannover Medical School, Carl-Neuberg-Straße 1, Hannover 30625, Germany. E-mail: neubert. lavinia@mh-hannover.de.

\begin{abstract}
Pulmonary hypertension and pulmonary vascular remodeling (PVR) are common in many lung diseases leading to right ventricular dysfunction and death. Differences in PVR result in significant prognostic divergences in both the pulmonary arterial and venous compartments, as in pulmonary arterial hypertension (PAH) and pulmonary veno-occlusive disease (PVOD), respectively. Our goal was to identify compartment-specific molecular hallmarks of PVR, considering the risk of life-threatening pulmonary edema in PVOD, if treated by conventional pulmonary hypertension therapy. Formalin-fixed and paraffin-embedded tissues from fresh explanted human lungs of patients with PVOD $(n=19)$, PAH $(n=20)$, idiopathic pulmonary fibrosis $(n=13)$, and chronic obstructive pulmonary disease $(n$ $=15)$, were analyzed for inflammation and kinome-related gene regulation. The generated neuronal network differentiated PVOD from PAH samples with a sensitivity of $100 \%$ and a specificity of $92 \%$ in a randomly chosen validation set, a level far superior to established diagnostic algorithms. Further, various alterations were identified regarding the gene expression of explanted lungs with PVR, compared with controls. Specifically, the dysregulation of microtubule-associated serine/ threonine kinase 2 and protein-o-mannose kinase SGK196 in all disease groups suggests a key role in pulmonary vasculopathy for the first time. Our findings promise to help develop novel target-specific interventions and innovative approaches to facilitate clinical diagnostics in an elusive group of diseases. (Am J Pathol 2020, 190: 1382-1396; https://doi.org/10.1016/j.ajpath.2020.03.008)
\end{abstract}

Pulmonary hypertension (PH) is a multifactorial pulmonary vascular disease leading to progressive right ventricular dysfunction and eventually to death by right heart failure. ${ }^{1}$ $\mathrm{PH}$ is defined by an abnormal elevation in the mean pulmonary arterial pressure of $>20 \mathrm{mmHg}$, as assessed by right heart catheterization. ${ }^{2}$ Furthermore, two hemodynamic parameters, pulmonary arterial wedge pressure and pulmonary vascular resistance, clinically subdivide $\mathrm{PH}$ into three categories: i) precapillary $\mathrm{PH}$, ii) isolated postcapillary $\mathrm{PH}$, and iii) combined precapillary and postcapillary $\mathrm{PH}$.

Pulmonary veno-occlusive disease (PVOD) [group 1.6 of the most recent clinical classification for $\mathrm{PH}$ : pulmonary arterial hypertension (PAH) with overt features of venous/ capillaries (PVOD/pulmonary capillary hemangiomatosis) involvement] represents a subgroup of $\mathrm{PAH}$ with exceptionally high mortality. ${ }^{2}$ In contrast to PAH, PVOD is predominantly characterized by fibrotic narrowing of pulmonary veins and venules leading to progressive $\mathrm{PH}$. Similarities in hemodynamic and physical findings complicate the distinction in the early stages between PVOD and PAH. ${ }^{3}$ About $5 \%$ to $10 \%$ of patients diagnosed with idiopathic PAH actually experience PVOD. ${ }^{4}$ Fibrotic

This project was funded by the CRC 738/3 (Project B9), the Central Innovation Programme for Small and Medium-Sized Enterprises (SMEs) grant ZF4549001CR8 (D.J. and M.K.), the KFO311 (Project Z2) (D.J.), the European Consolidator Grant 771883 [Hanover experimental lung research project (XHaLe)] (D.J.), and the German Center for Lung Research (DZL).

L.N. and P.B. contributed equally to this work.

M.K. and D.J. contributed equally to this work as senior authors.

Disclosures: M.M.H. has received honoraria for lectures and consultations from Actelion, Bayer, GSK, MSD and Pfizer, all unrelated to the submitted work. 
narrowing and obliteration of pulmonary veins are associated with the risk of developing a life-threatening pulmonary edema, especially when medical therapy for PAH is initiated. ${ }^{5}$ Progressive mediastinal lymph node enlargement, interlobular septal thickening, and centrilobular ground-glass opacities evident in high-resolution computed tomography images during pharmaceutical treatment of patients with PH can help identify alterations of the postcapillary pulmonary vasculature in the right setting ${ }^{6}$ (Figure 1).

Pulmonary vascular remodeling with a manifestation of $\mathrm{PH}$ is also present in chronic obstructive pulmonary disease (COPD) and some diffuse parenchymal lung diseases such as idiopathic pulmonary fibrosis (IPF). In all of these conditions, the development of $\mathrm{PH}$ is associated with a worse outcome. ${ }^{7}$ Unfortunately, the pathogenesis of pulmonary vascular remodeling in chronic lung disease remains poorly understood. Until now, lung transplantation remains the only "curative" therapy for PVOD and other nonneoplastic end-stage lung diseases with severe pulmonary vascular remodeling (Figure 2).

Perivascular inflammation in $\mathrm{PH}$ is currently discussed as a trigger of smooth muscle and endothelial cell proliferation by circulating cytokines and chemokines. ${ }^{8}$ To better understand the formation of vascular lesions and to identify potential molecular drug targets, the current study investigated freshly explanted human lungs from patients with PAH, PVOD, COPD, and IPF. These diseases were studied by using NanoString technology focusing on kinome- and inflammation-related genes; importantly, the exact aspects of the inflammatory component of progressive pulmonary vasculopathy, despite its unquestionable relevance, remain largely unknown. ${ }^{9}$ Moreover, we aimed to generate a molecular diagnostic model to differentiate between PAH and PVOD, and we representatively validated the identified mRNA profiles of critical ones with protein expression levels using mass spectrometry and multiplex immunohistochemistry.

\section{Materials and Methods}

\section{Evaluation of Fresh Human Lung Explants}

All studies were performed in accordance with the requirements of our local ethics committee (ethics vote no. 2702-2015). All available human lung explants were obtained from patients with severe pulmonary vascular remodeling due to PVOD, PAH, IPF, and COPD, who underwent lung transplantation at Hannover Medical School during the period 2005 until 2018. The pulmonary explants were immediately picked up from the operating theater, inflated, and worked up in a separate lung laboratory by experienced and specialized pulmonary pathologists around the clock in a standardized manner, according to standard operating procedures. ${ }^{10}$ Hereby, we were able to achieve cold ischemia times $<25$ minutes and highly standardized

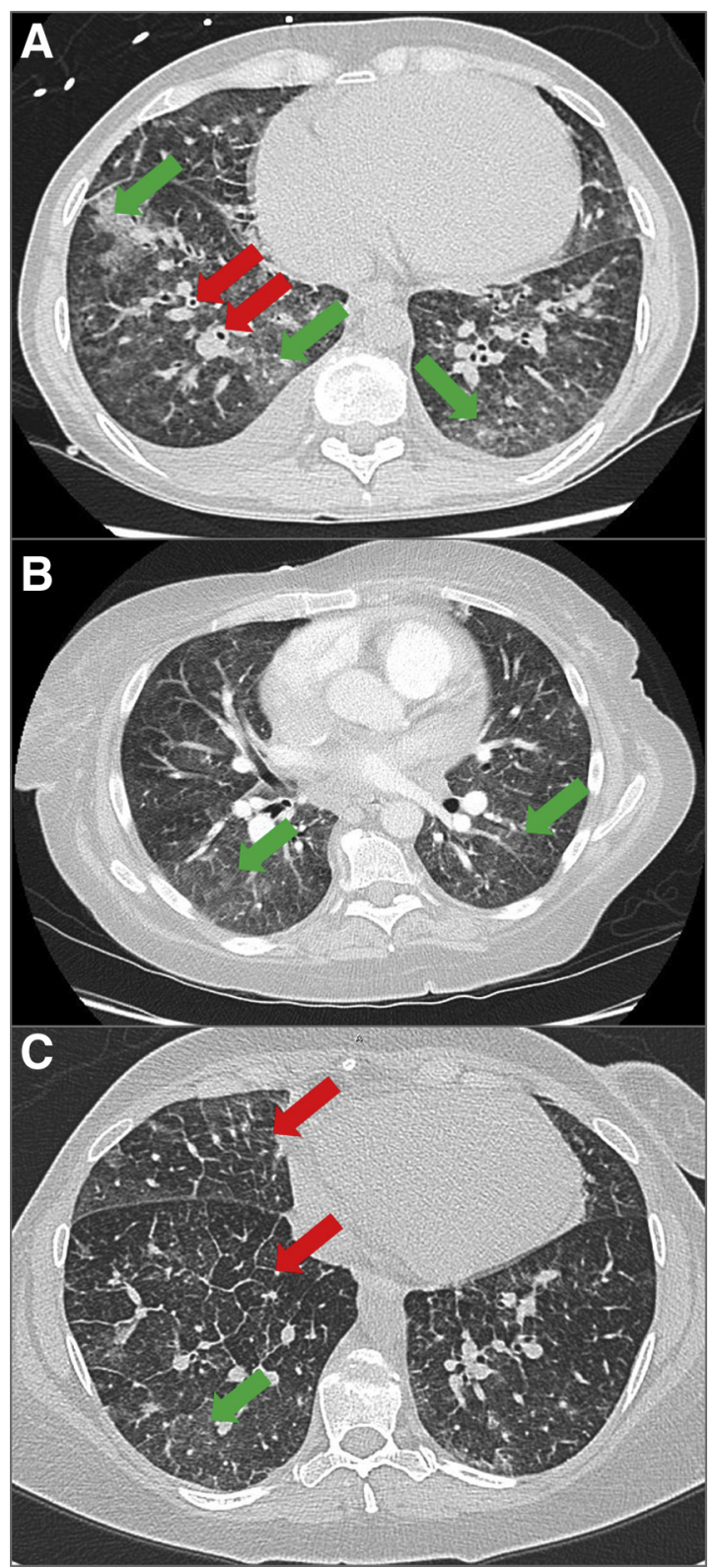

Figure 1 Transverse high-resolution computed tomography images obtained with $1.2 \mathrm{~mm}(\mathbf{A}), 3.8 \mathrm{~mm}(\mathbf{B})$, and $1 \mathrm{~mm}(\mathbf{C})$ section thickness. A: Patient with pulmonary veno-occlusive disease (PVOD) and intermittent hemorrhages (green arrows), pleural effusions, and bronchial thickening (red arrows). B: Patient with PVOD and ground-glass opacities (green arrows). C: Patient with PVOD and intermittent edema/hemorrhages (green arrow) and interstitial thickening (red arrows).

samples. Formalin-fixation and paraffin-embedding (FFPE) represents the gold standard for high-quality histopathologic assessment, being far superior for identifying minute pathologic changes, for example, compared with frozen sections. Because morphologic changes (especially in PVOD) tend to be discrete and difficult to identify, even for experienced pathologists, FFPE specimens, rather than frozen samples, were used for the current study. For further analysis, FFPE tissue was cut by using a routine microtome and stained with hematoxylin and eosin, Periodic acid-Schiff, and 


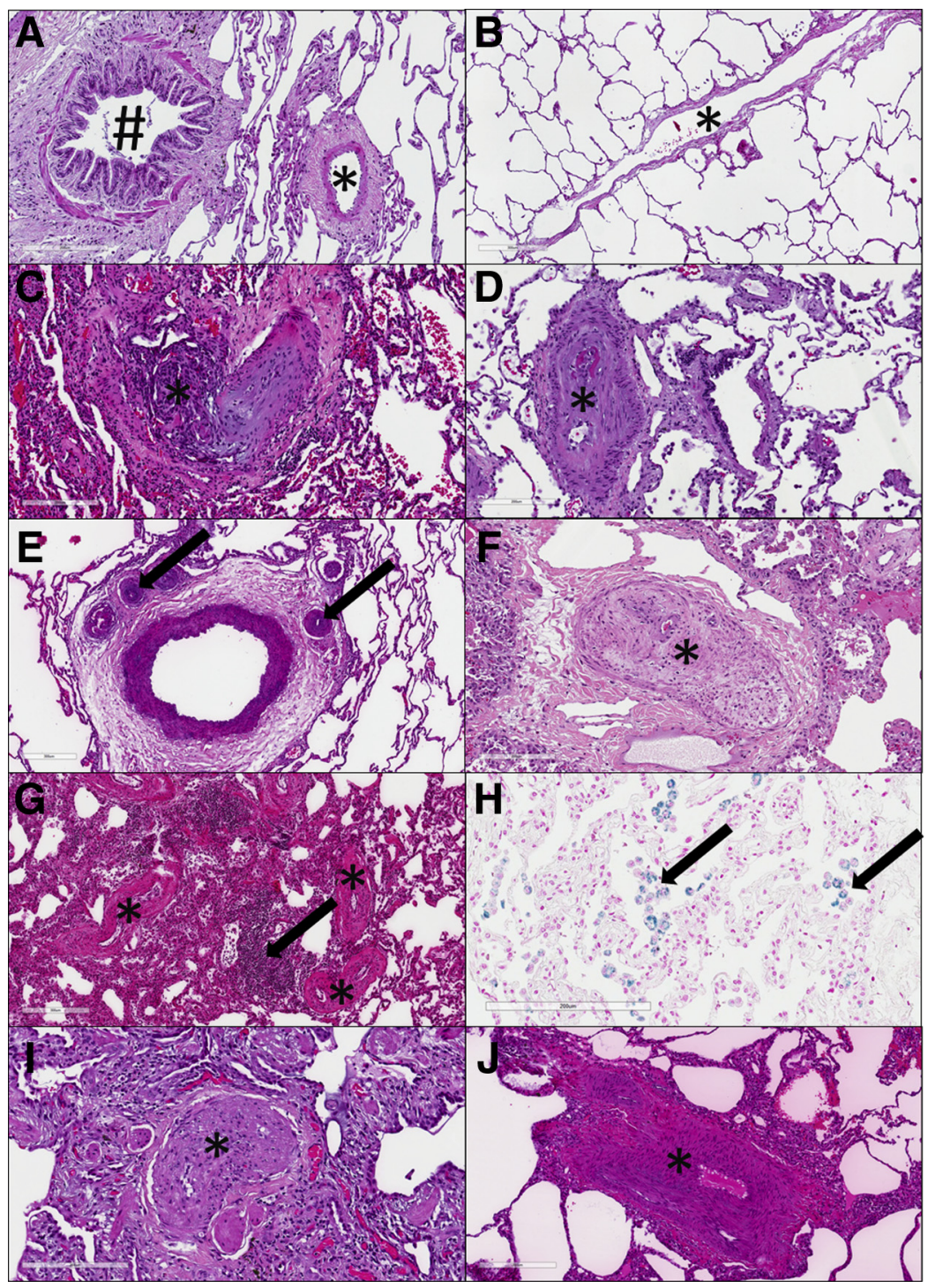

Figure 2 A: Physiologic pulmonary artery (asterisk) next to the bronchioles (hash mark). B: Physiologic pulmonary vein (asterisk). C: Plexiform vasculopathy (asterisk) in idiopathic pulmonary arterial hypertension (IPAH). D: Concentric remodeling (asterisk) of a pulmonary artery in IPAH. E: Narrowing and occlusion of the vasa vasorum of a pulmonary artery (arrows) in IPAH. F: Occluded pulmonary vein (asterisk) in pulmonary venoocclusive disease (PVOD). G: Dense lymphohistiocytic infiltrates (arrow) next to remodeled pulmonary venules (asterisks) in PVOD. H: Hemosiderin-laden alveolar macrophages (arrows) in PVOD. I: Remodeled pulmonary artery (asterisk) in idiopathic pulmonary fibrosis. J: Remodeled pulmonary artery (asterisk) in chronic obstructive pulmonary disease. Scale bars: $200 \mu \mathrm{m}($ A, C, $\mathbf{D}, \mathbf{F}$, and $\mathbf{H}-\mathbf{J}) ; 300 \mu \mathrm{m}$ (B, E, and $\mathbf{G}$ ).

Elastica van Gieson for histopathologic evaluation. The most representative areas in each lung were identified by histopathologic analysis.

\section{RNA Extraction and Statistical Analysis}

The target areas were sampled by using a punch with a diameter of $6 \mathrm{~mm}$. RNA was then isolated from at least ten 5$\mu \mathrm{m}$ thick FFPE slices via the Maxwell 16 LEV RNA FFPE Purification Kit (Promega Corporation, Madison, WI). RNA content was measured by using the Qubit RNA IQ Assay (Thermo Fisher Scientific, Waltham, MA) ensuring a minimum RNA concentration of $200 \mathrm{ng}$ per sample. RNA samples were measured by using commercial gene-specific inflammation and kinase panels (536/255 target genes) via the nCounter Analysis System (NanoString Technologies, Seattle, WA), which has been optimized for FFPE-based experiments. The nCounter system quantifies gene expression directly, without the amplification steps necessary in quantitative real-time polymerase chain reaction. Moreover, this method yields far more reliable and exact results compared with those of quantitative real-time polymerase chain reaction-based microarrays. ${ }^{11}$ Normalization of counts was performed by using the nSolver analysis software version 3.0 (NanoString Technologies, Seattle, WA) and included positive normalization (geometric mean), negative normalization (arithmetic mean), and reference normalization (geometric mean). Glyceraldehyde-3-phosphate dehydrogenase $(G A P D H)$, glucoronidase beta $(G U S B)$, hypoxanthine phosphoribosyltransferase 1 (HPRT1), phosphoglycerate kinase 1 $(P G K 1)$, and tubulin beta class I (TUBB) were designated as reference genes. Data from both panels were merged in the nSolver software via definition of a MultiRLF experiment, thus centering on 28 genes that include reference gene expression to probes that were common to both (Supplemental Table S1). Further analysis of the resulting $\log _{2}$ mRNA counts was performed by using the $\mathrm{R}$ software version 3.4.4 (R Foundation for Statistical Computing, Vienna, Austria; 
http://www.r-project.org, last accessed March 1, 2018) and partial code of the nCounter Advanced Analysis module version 1.1.5. ${ }^{12}$ A Shapiro-Wilks test performed on all intragroup gene expressions showed that a considerable fraction of the data were not normally distributed $(19 \% ; \alpha=0.05)$. To identify significant changes in gene expression, $U$-tests were used for pairwise comparisons between groups, and KruskalWallis tests were used for multigroup comparisons. Statistical analysis was concluded by correction for multiple testing (Bonferroni method). Changes with corrected $P$ values $<0.05$ were considered as significant. For a functional analysis of gene expression profiles, false discovery rates (FDRs) were calculated instead of Bonferroni-corrected $P$ values.

\section{Classification Analysis}

One of the study goals was to determine whether a differentiation between PAH and PVOD is feasible by detection of absolute mRNA levels in FFPE tissue on the basis of the two NanoString panels used. Therefore, a variety of binary classifiers were trained by using different gene sets and classification algorithms (Supplemental Table S2).

First, PAH and PVOD samples $(n=20 / 19)$ were randomly assigned into a fixed training set $(n=8 / 7)$ and a test set ( $n=12 / 12$ ), using the method "sample" from the R programming environment. The training set was used as input for multiple machine learning algorithms ( $\mathrm{R}$ package caret version 6.0-81; algorithms used, lda, rf, mlpML, nnet, multinom, svmLinear, and svmRadial; https://cran.r-project.org/web/ packages/caret/index.html, last accessed November 20, 2018). The option "tuneLength" was increased from its default value of 3 to 15 to further improve tuning of individual model parameters. For resampling and estimating preliminary model performance, leave-one-out cross-validation was used. Optimal combinations of gene subsets as input variables (up to a number of 16 genes) were identified via an exact leaps and bounds algorithm aimed at optimizing the Tau-squared coefficient (R package subselect version 0.14; https://cran.r-project. org/web/packages/subselect/index.html, last accessed January 29,2018 ) or via the random forest importance metric in case of random forest models. Gene subset selection was also limited to significantly regulated genes, and genes whose expression was highly correlated (correlation $\geq 0.9$ ) were removed in a stepwise manner before subset selection. The final model accuracy was evaluated based on the performance of each model against the test set. In the same manner, a multiclass model was created for the classification of all entities in this work (controls, COPD, IPF, PAH, and PVOD) as well as binary models to discriminate each individual entity from all remaining samples using a common test set (Supplemental Table S3).

\section{Functional Analysis}

The comparison analysis module was used from the Ingenuity Pathway Analysis tool (IPA, Qiagen Inc., Venlo, the Netherlands) to complement the study's molecular data with predictions on the activation/inhibition of biological functions and diseases. ${ }^{13}$ For this purpose, the relative gene expression profile of each individual sample compared with the median gene expression in the control samples was used as input, limited to significantly regulated genes compared with control samples (FDR $<0.05$ ). The analysis was performed with default settings and therefore used information from both in vivo and in vitro experiments. The IPA tool calculates $z$ scores as a quantitative estimate for the confidence that a biological function is either activated (positive $z$ score) or inactivated (negative $z$ score). Significant differences in the predicted regulation of biological functions were determined via pairwise $U$-tests and multigroup KruskalWallis tests. $P$ values were considered to be significant according to the following levels of confidence: ${ }^{*} P<0.05$, $* * P<0.01, * * * P<0.001$, and $* * * * P<0.0001$.

\section{Label-Free Quantitative Proteomics}

Complementary fresh frozen lung samples were collected from our study subjects, consisting of 5 patients with PVOD, 5 with PAH, 5 with IPF, 4 with COPD, and 5 healthy control subjects. The samples were obtained from a $-80^{\circ} \mathrm{C}$ freezer for label-free quantitative proteomics to validate the identified disease-specific mRNA profiles with protein expression.

Frozen lung samples were homogenized in a CryoMill (Retsch, Haan, Germany) using a $25-\mathrm{mL}$ grinding jar containing a single $20-\mathrm{mm}$ steel ball at a frequency of 25 oscillations per second, for a period of 90 seconds. Proteins were extracted from the ground tissue in a buffer containing 4\% (w/v) SDS, $125 \mathrm{mmol} / \mathrm{L}$ Tris-hydrochloride ( $\mathrm{pH} \mathrm{6.8),}$ and $20 \%(\mathrm{v} / \mathrm{v})$ glycerol, which was heated to $60^{\circ} \mathrm{C}$ for 5 minutes. ${ }^{14}$ After centrifugation at $18,000 \times g$ for 10 minutes, the protein concentration of each sample was determined with the Pierce BCA Protein Assay kit (Thermo Fisher Scientific, Dreieich, Germany) before a volume equivalent to $50 \mu \mathrm{g}$ of protein was supplemented with a mixture of $\beta$-mercaptoethanol and bromophenol resulting in final concentrations of $5 \%(\mathrm{v} / \mathrm{v})$ and $0.5 \%(\mathrm{v} / \mathrm{v})$, respectively. The samples were then submitted to polyacrylamide gel electrophoresis in a glycine-SDS gel consisting of a $4 \%$ stacking gel and a $14 \%$ separation gel. As soon as the dye front reached the phase border, electrophoresis was stopped. After Coomassie staining, the resulting gel band containing the concentrated proteins was excised from the gel and subjected to an in-gel trypsin-based digestion protocol as described in Fromm et al. ${ }^{15}$

Tandem mass spectrometry using a top-10 method was performed by using a Q-Exactive mass spectrometer coupled to an Ultimate 3000 UHPLC (both, Thermo Fisher Scientific, Dreieich, Germany). Dried peptides were taken up in $20 \mu \mathrm{L}$ of a solution containing $5 \%$ acetonitrile, $0.1 \%$ trifluoroacetic acid of which $1 \mu \mathrm{L}$ was loaded onto a $2-\mathrm{cm}$

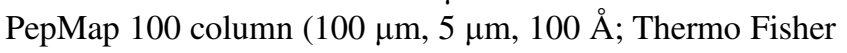


Scientific) coupled to a 50-cm PepMap 100 column $(75 \mu \mathrm{m}$, $3 \mu \mathrm{m}, 100 \AA$ A Thermo Fisher Scientific). Peptides were eluted during a 4-hour acetonitrile gradient (nonlinear, from $5 \%$ to $36 \%$ acetonitrile, containing $0.1 \%$ formic acid). The eluted peptides were desolvated and archived in an NSI source (Thermo Fisher Scientific) at $2.2 \mathrm{kV}$ using stainless steel emitters (Thermo Fisher Scientific) and at a capillary temperature of $275^{\circ} \mathrm{C}$. Mass spectrometry settings were similar to those reported in Fromm et al. ${ }^{15}$

Raw mass spectrometry data were queried against an inhouse database including all known human protein sequences (RefSeq Proteins for latest build of genome GRCh38 from November 2019), using the Andromeda search engine as part of the MaxQuant software package. ${ }^{16}$ Settings were the same as reported by Fromm et al. ${ }^{15}$ The pairwise statistical comparison of $\log 2$-transformed label-free quantitation values between individual groups was conducted by using the $U$-test followed by calculation of FDRs. Any FDR $\leq 0.05$ was considered statistically significant.

Mapping of RNA transcripts and proteins to gene symbols was performed by using the $\mathrm{R}$ package org.Hs.eg.db version 3.5.0 (https://bioconductor.org/packages/release/data/annota tion/html/org.Hs.eg.db.html, last accessed April 24, 2017).

Pathway analysis of proteome data Log2-tranformed label-free quantitation values of the significantly dysregulated proteins in each disease were relativized to control samples, and a pathway analysis was implemented by using Ingenuity Pathway Analysis (Qiagen Bioinformatics, Redwood City, CA). $Z$ scores that serve as quantitative estimates for the activation or inactivation of diseases and functions were calculated by Ingenuity Pathway Analysis software.

\section{Multiplex Immunohistochemistry}

To further correlate compartment-specific protein expression with disease-specific mRNA expression, FFPE slices for each study group (PAH, COPD, IPF, PAH, and control) were representatively stained by using Opal 7-plex technology (Akoya Biosciences, Marlborough, MA), as previously described by Mascaux et al. ${ }^{17}$ Thereby, the six markers - C-C chemokine receptor type 7 (CCR7), transforming growth factor- $\beta$ (TGF- $\beta$ ), Gardner-Rasheed feline sarcoma viral (v-fgr) oncogene (FGR), ABL protooncogene 2 (ABL2), protein O-mannose kinase SGK196 (SGK196) and microtubule-associated serine/threonine kinase 2 (MAST2) - were selected as outlined by the disease-specific mRNA profile and could be visualized simultaneously on the same slide (Table 1). The slices were then scanned and analyzed by using the Akoya Biosciences Vectra 3 System and inForm Advanced Image Analysis software version 2.3.0 (Akoya Biosciences, Marlborough, MA). Vascular and perivascular stamps were defined as regions of interest. The number of analyzed stamps were 41 for COPD, 46 for PAH, 29 for control, 28 for IPF, and 58 for PVOD. The entire cell count of positive cells was normalized to the total cell count in each stamp. Bonferroni multiple comparison tests were implemented for pairwise comparisons between groups.

\section{Results}

\section{Study Groups}

By histopathologic assessment of the pulmonary explants, five study groups were created that focused on the predominant compartment-specific affection of the pulmonary vasculature: one "PVOD" group $(n=19)$, one "PAH" group $(n=20)$, one "IPF" group $(n=13)$ one "COPD" group $(n=15)$, and one "control" group using human pulmonary downsizing specimens from lung donors, sampled before transplantation $(n=16)$. Information about patient age at transplantation and patient's sex is shown in

Table 1 Target Antibodies Used for Multiplex Immunohistochemistry

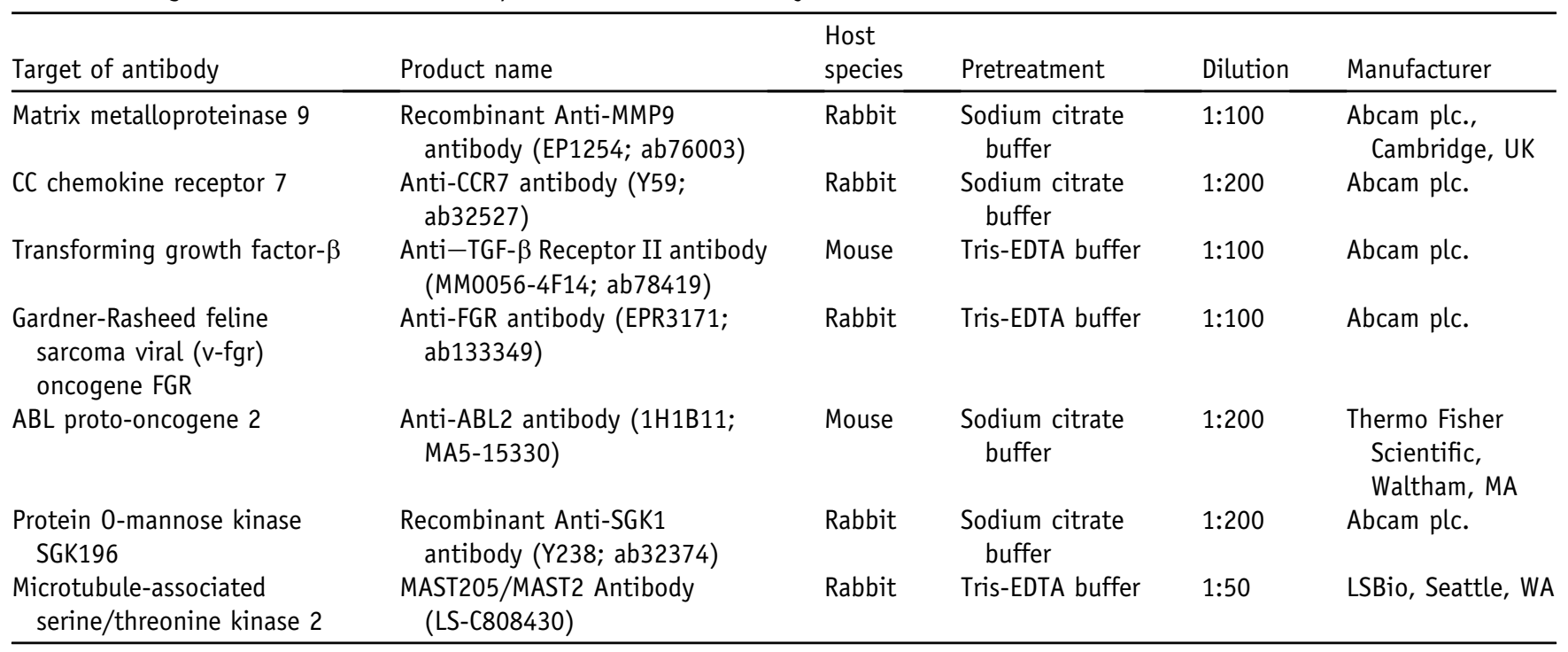


Table 2 Clinical Information of the Study Groups

\begin{tabular}{|c|c|c|c|}
\hline Study group & $\begin{array}{l}\text { Patient } \\
\text { ID }\end{array}$ & Sex & $\begin{array}{l}\text { Age at } \\
\text { transplantation, } \\
\text { years }\end{array}$ \\
\hline \multirow{19}{*}{$\begin{array}{l}\text { Pulmonary veno- } \\
\text { occlusive disease, } \\
n=19 \text { ( } 17 \text { female } \\
\text { subjects and } \\
2 \text { male subjects); } \\
\text { means } \pm S D \text { age at } \\
\text { transplantation, } \\
38 \pm 15 \text { years }\end{array}$} & $\mathrm{P} 1$ & $\mathrm{~F}$ & 39 \\
\hline & $\mathrm{P} 2$ & $\mathrm{~F}$ & 29 \\
\hline & P3 & $\mathrm{F}$ & 32 \\
\hline & P4 & $\mathrm{F}$ & 49 \\
\hline & P5 & $M$ & 52 \\
\hline & P6 & $\mathrm{F}$ & 40 \\
\hline & P23 & $\mathrm{F}$ & 47 \\
\hline & P24 & $\mathrm{F}$ & 43 \\
\hline & P35 & $\mathrm{F}$ & 13 \\
\hline & P33 & $\mathrm{F}$ & 49 \\
\hline & P53 & $\mathrm{F}$ & 21 \\
\hline & P52 & $\mathrm{F}$ & 36 \\
\hline & P65 & $\mathrm{F}$ & 60 \\
\hline & P72 & $\mathrm{F}$ & 40 \\
\hline & P81 & $\mathrm{F}$ & 58 \\
\hline & P82 & $M$ & 11 \\
\hline & P83 & $\mathrm{F}$ & 20 \\
\hline & P88 & $\mathrm{F}$ & 20 \\
\hline & P90 & $\mathrm{F}$ & 59 \\
\hline \multirow{20}{*}{$\begin{array}{l}\text { Pulmonary arterial } \\
\text { hypertension, } \\
n=20 \text { ( } 17 \text { female } \\
\text { subjects and } \\
3 \text { male subjects); } \\
\text { means } \pm \text { SD age at } \\
\text { transplantation, } \\
27 \pm 16 \text { years }\end{array}$} & P15 & $\mathrm{F}$ & 25 \\
\hline & P16 & $M$ & 10 \\
\hline & P17 & $\mathrm{F}$ & 53 \\
\hline & P18 & $\mathrm{F}$ & 36 \\
\hline & P19 & $\mathrm{F}$ & 25 \\
\hline & P20 & M & 4 \\
\hline & P21 & $\mathrm{F}$ & 26 \\
\hline & $\mathrm{P} 22$ & $\mathrm{~F}$ & 47 \\
\hline & P46 & $\mathrm{F}$ & 26 \\
\hline & P47 & $\mathrm{F}$ & 50 \\
\hline & P54 & $\mathrm{F}$ & 2 \\
\hline & P55 & $\mathrm{F}$ & 17 \\
\hline & P62 & $\mathrm{F}$ & 10 \\
\hline & P70 & $\mathrm{F}$ & 14 \\
\hline & P85 & $\mathrm{F}$ & 31 \\
\hline & P86 & $\mathrm{F}$ & 20 \\
\hline & P91 & $\mathrm{F}$ & 17 \\
\hline & P93 & $\mathrm{F}$ & 41 \\
\hline & P94 & $\mathrm{F}$ & 56 \\
\hline & P95 & M & 26 \\
\hline \multirow{14}{*}{$\begin{array}{l}\text { Idiopathic pulmonary } \\
\text { fibrosis, } n=13 \text { ( } 3 \\
\text { female subjects and } \\
10 \text { male subjects); } \\
\text { means } \pm \text { SD age at } \\
\text { transplantation, } \\
59 \pm 4 \text { years }\end{array}$} & P25 & $M$ & 54 \\
\hline & P26 & $\mathrm{F}$ & 63 \\
\hline & P27 & $M$ & 64 \\
\hline & P28 & $M$ & 59 \\
\hline & P29 & $\mathrm{F}$ & 53 \\
\hline & P30 & $M$ & 60 \\
\hline & P31 & $M$ & 60 \\
\hline & P32 & $M$ & 56 \\
\hline & P48 & $M$ & 52 \\
\hline & P59 & $M$ & 57 \\
\hline & P60 & $M$ & 65 \\
\hline & P64 & $M$ & 59 \\
\hline & P69 & $\mathrm{F}$ & 61 \\
\hline & & & (table $\mathrm{c}$ \\
\hline
\end{tabular}

Table 2 (continued)

\begin{tabular}{|c|c|c|c|}
\hline Study group & $\begin{array}{l}\text { Patient } \\
\text { ID }\end{array}$ & Sex & $\begin{array}{l}\text { Age at } \\
\text { transplantation, } \\
\text { years }\end{array}$ \\
\hline \multirow{15}{*}{$\begin{array}{l}\text { Chronic obstructive } \\
\text { pulmonary disease, } \\
n=15 \text { ( } 5 \text { female } \\
\text { subjects and } 10 \\
\text { male subjects); } \\
\text { means } \pm \text { SD age at } \\
\text { transplantation, } \\
56 \pm 5 \text { years }\end{array}$} & P37 & $M$ & 62 \\
\hline & P38 & $\mathrm{F}$ & 58 \\
\hline & P39 & $\mathrm{F}$ & 55 \\
\hline & P40 & $\mathrm{F}$ & 56 \\
\hline & P41 & M & 54 \\
\hline & P42 & M & 53 \\
\hline & P43 & M & 58 \\
\hline & P44 & M & 66 \\
\hline & P45 & M & 63 \\
\hline & P57 & M & 55 \\
\hline & P56 & $\mathrm{F}$ & 54 \\
\hline & P58 & $M$ & 49 \\
\hline & P63 & M & 55 \\
\hline & P67 & $M$ & 59 \\
\hline & P68 & $\mathrm{F}$ & 46 \\
\hline \multirow{16}{*}{$\begin{array}{l}\text { Control, } n=16 \text {; age } \\
\text { and sex remain } \\
\text { unknown, } \\
\text { respecting the } \\
\text { anonymity of the } \\
\text { donor }\end{array}$} & P7 & Unknown & Unknown \\
\hline & P8 & Unknown & Unknown \\
\hline & P9 & Unknown & Unknown \\
\hline & P10 & Unknown & Unknown \\
\hline & P11 & Unknown & Unknown \\
\hline & P12 & Unknown & Unknown \\
\hline & P13 & Unknown & Unknown \\
\hline & P14 & Unknown & Unknown \\
\hline & P34 & Unknown & Unknown \\
\hline & P36 & Unknown & Unknown \\
\hline & P49 & Unknown & Unknown \\
\hline & P50 & Unknown & Unknown \\
\hline & P51 & Unknown & Unknown \\
\hline & P61 & Unknown & Unknown \\
\hline & P66 & Unknown & Unknown \\
\hline & P71 & Unknown & Unknown \\
\hline
\end{tabular}

F, female; $M$, male.

Table 2. Clinical information regarding the control group is not available, respecting the anonymity of the donors.

\section{Histopathology}

Histopathologic assessment of standardized samples was performed by using a routine light microscope, and findings were interpreted in correlation with the clinical course of disease (Figure 2). Morphologic features of PAH included intimal proliferation, muscular hypertrophy, concentric intimal lesions, plexiform lesions, angiomatoid lesions, and dilatation and necrotizing vasculitis of pulmonary arteries and arterioles. ${ }^{18}$ In contrast, PVOD was characterized by a predominant alteration of the postcapillary pulmonary vasculature, as indicated by venous intimal fibrosis and medial hypertrophy, venous intraluminal septa or recanalization, interlobular septal thickening, a mild interstitial lymphocytic infiltrate and fibrosis, capillary congestion and proliferation, 
hemosiderosis, and venulitis but usually only mild arterial intimal fibrosis and medial hypertrophy. ${ }^{19}$ Patients with IPF exhibited the characteristic histopathologic features of usual interstitial pneumonia, with heterogeneous fibrotic remodeling, honeycombing cysts, dominant interstitial fibrosis, fibroblastic foci, and disorganized smooth muscle proliferation next to areas of nonremodeled lung tissue ${ }^{20}$ COPD lung explants exhibited severe airway inflammation and peribronchial fibrosis, as well as severe emphysematous rarefication of the alveolar septa. ${ }^{21}$

\section{Gene Expression Analysis}

The absolute gene expression values for each disease entity analyzed in this work were compared with those of the healthy control samples (Figure 3 and Supplemental Table S1). All entities were characterized by an increased expression of MAST2 and SGK196 (alias POMK). PVOD lung explants revealed 10 dysregulated genes; that is an increased expression of MAST2, microtubule affinity regulating kinase 1 (MARK 1), SGK196, and high mobility group nucleosome binding domain 1 (HMGN1) and a decreased expression of matrix metalloproteinase 9 (MMP9), interleukin 10 (IL10), C-X-C motif chemokine receptor $1(C X C R 1), \mathrm{C}-\mathrm{X}-\mathrm{C}$ motif chemokine receptor 2 $(C X C R 2), F G R$, and interleukin 18 receptor accessory protein (IL-18RAP). The decreased expression of MMP9 was unique to PVOD. PAH lung explants revealed 93 dysregulated genes compared with control samples, including a unique dysregulation of 50 genes. IPF lung explants revealed 46 dysregulated genes compared with control samples with a unique dysregulation of 24 genes. COPD lung explants revealed 60 dysregulated genes compared with control samples. Thereby, a dysregulation of 17 genes was unique for COPD. Patient age and sex had no significant effect on intragroup gene expression (tested with $U$-test and Spearman correlation, FDR $<0.1$ ).

T-distributed stochastic neighbor embedding analysis revealed that $\mathrm{PAH}$ and PVOD samples exhibited the greatest degree of intragroup heterogeneity in gene expression, whereas control samples, COPD samples, and IPF samples were highly homogenous within groups (Supplemental Figure S1).

\section{Classification Analysis}

The classification analysis yielded a feed-forward neural network with a single hidden layer, which allows for the differentiation of PVOD and conventional PAH samples with a high accuracy of $96 \%$ (Figure 4). The model structure and a comprehensive description of the identified neuronal network can be found on Mendeley: https://data.mendeley.com/

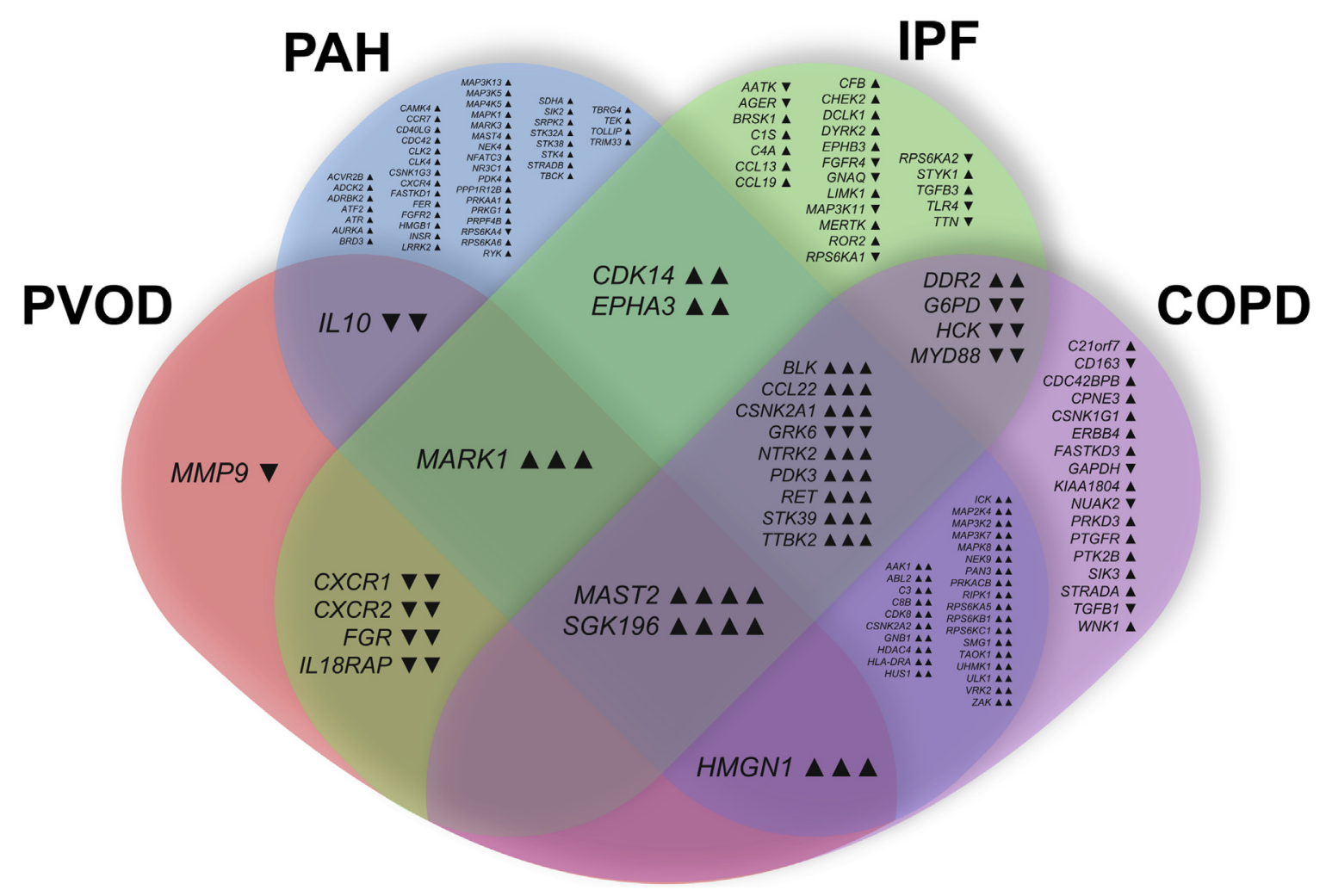

Figure 3 Venn diagram of differentially regulated genes in chronic obstructive pulmonary disease (COPD), idiopathic pulmonary fibrosis (IPF), pulmonary arterial hypertension (PAH), and pulmonary veno-occlusive disease (PVOD) compared with control samples. The up-regulation and down-regulation of significantly differentially expressed genes are indicated by arrowheads (up arrowheads and down arrowheads, respectively). In intersection areas of two or more entities, arrowheads are representative for a single entity each and ordered accordingly: PVOD > PAH > IPF > COPD. 


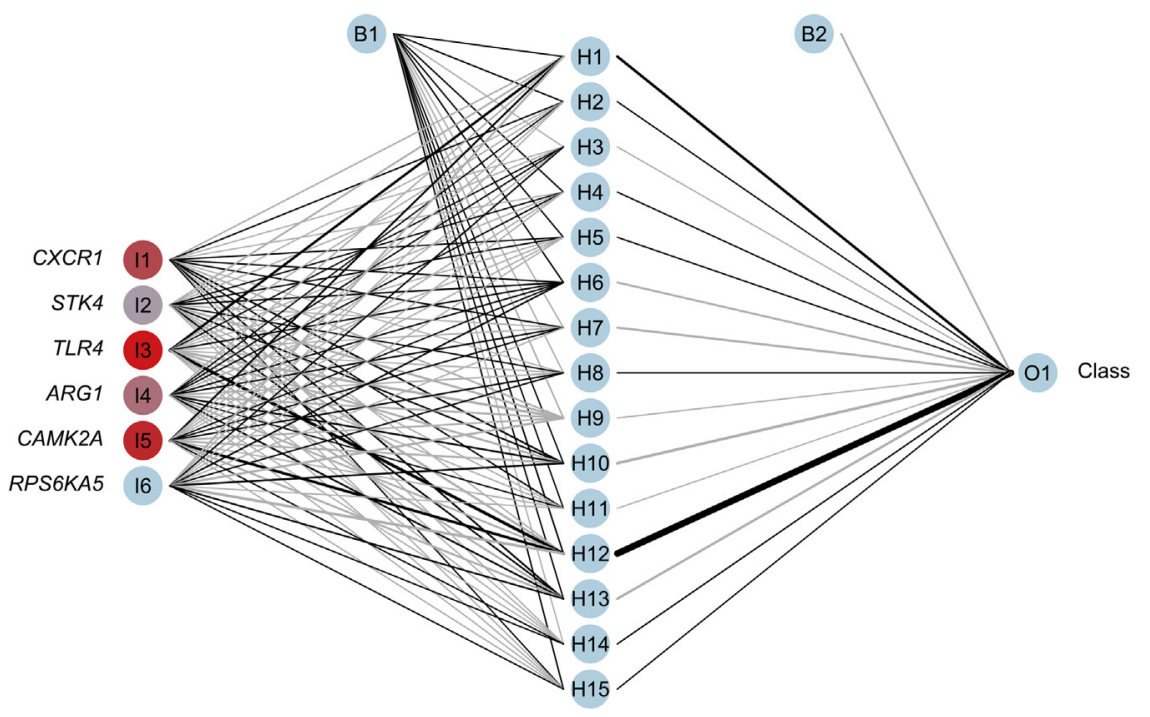

Figure 4 The expression of six genes is used as input for the neuronal network. The node color of the input variables indicates the relative contribution of the variables to the hidden layer (low $=$ light blue; high $=$ red). The weights of the network are visualized via edge width and color (black edge $=$ positive weight, gray edge $=$ negative weight). $\mathrm{B}$, bias; $\mathrm{H}$, hidden; $\mathrm{I}$, input; 0 , outcome. datasets/h9nw4 cxcs $8 / 2$ (last accessed March 18, 2020). The six genes required as input for our model were bioinformatically identified as near-optimal choice via an exact leaps-and-bounds algorithm: C-X-C motif chemokine receptor $1(C X C R l)$, serine/threonine kinase 4 (STK4), tolllike receptor 4 (TLR4), arginase $1(A R G 1)$, calcium/calmodulin dependent protein kinase II alpha chain (CAMK2A), and ribosomal protein S6 kinase A5 (RPS6KA5). Thereby, all 12 PVOD samples in the test set were correctly identified as PVOD with a sensitivity of $100 \%$. The specificity for the prediction of PVOD was $92 \%$ because one of $12 \mathrm{PAH}$ samples from the test set was falsely labeled as PVOD. However, no PVOD sample was labeled as PAH, and thus 11 of $12 \mathrm{PAH}$ samples were identified as $\mathrm{PAH}$, which equals a sensitivity of $92 \%$ and a specificity of $100 \%$.

\section{Functional Analysis}

A functional analysis of the differential regulation of biological functions and pathways between the disease entities analyzed by using the IPA tool showed numerous differences between PAH and COPD. This is in contrast to the comparison of PVOD and IPF (Supplemental Table S4). The IPA tool was able to predict regulation scores for 97 biological functions, of which 44 were relevant to the disease entities researched in this work. Remarkably, PVOD shared 11-fold more similarities with IPF, compared with $\mathrm{PAH}$, measured by the amount of nonsignificantly regulated functions between entities (11 compared with 1). The predicted regulation of biological pathways (Table 3 ) showed a down-regulation of IL-6 signaling, as well as of IL-8 signaling, nuclear factor 'kappa-light-chain-enhancer' of activated B cells (NF- $\kappa \mathrm{B})$ signaling, and p-58 mitogenactivated protein kinase signaling but an activation of peroxisome proliferator-activated receptor signaling for PVOD and IPF. In contrast, the prediction revealed activation of IL-6 signaling, IL-8 signaling, nuclear factor kappa-light-chain-enhancer of activated B cells (NF- $\kappa \mathrm{B})$ signaling, and p-58 mitogen-activated protein kinase signaling but an inactivation of peroxisome proliferatoractivated receptor signaling in lungs from patients with PAH and COPD.

\section{Label-Free Quantitative Proteomics and Multiplex Immunohistochemistry}

In total, 1653 unique proteins could be identified via mass spectrometry and mapped to 1408 distinct genes (Supplemental Table S5); 86 dysregulations were shown between diseases and controls on the protein level (Figure 5). Regarding the overlap between the analyzed mRNAs by NanoString panels and the detected proteins by mass spectrometry, 47 genes from the NanoString panels could also be identified on the protein level by mass spectrometry (47 of 1408). Among these overlapping 47 genes, 13 genes are significantly dysregulated on the mRNA level: complement component 1s $(C 1 S)$, complement component 3 (C3), complement $\mathrm{C} 8$ beta chain $(C 8 B)$, cluster of differentiation 163 (CD163), complement factor $\mathrm{B}(C F B)$, copine-3 (CPNE3), casein kinase 2 alpha 1 (CSNK2A1/ $C S N K 2 A 3)$, glucose-6-phosphate dehydrogenase (G6PD), major histocompatibility complex, class II, DR alpha (HLA$D R A)$, complement component 4A $(C 4 A)$, matrix metalloproteinase 9 (MMP9), protein kinase cGMP-dependent 1 $(P R K G 1)$, and succinate dehydrogenase (SDHA) (Figure 3).

The MMP9 gene and the succinate dehydrogenase (SDHA) gene were significantly dysregulated between diseases and controls on both the protein and the mRNA level (Figures 3 and 5).

The functional analysis of proteomics data by IPA revealed a pro-apoptotic, pro-necrotic, and cancer-like pulmonary environment with increased cell stress and 
Table 3 Regulation of Biological Pathways

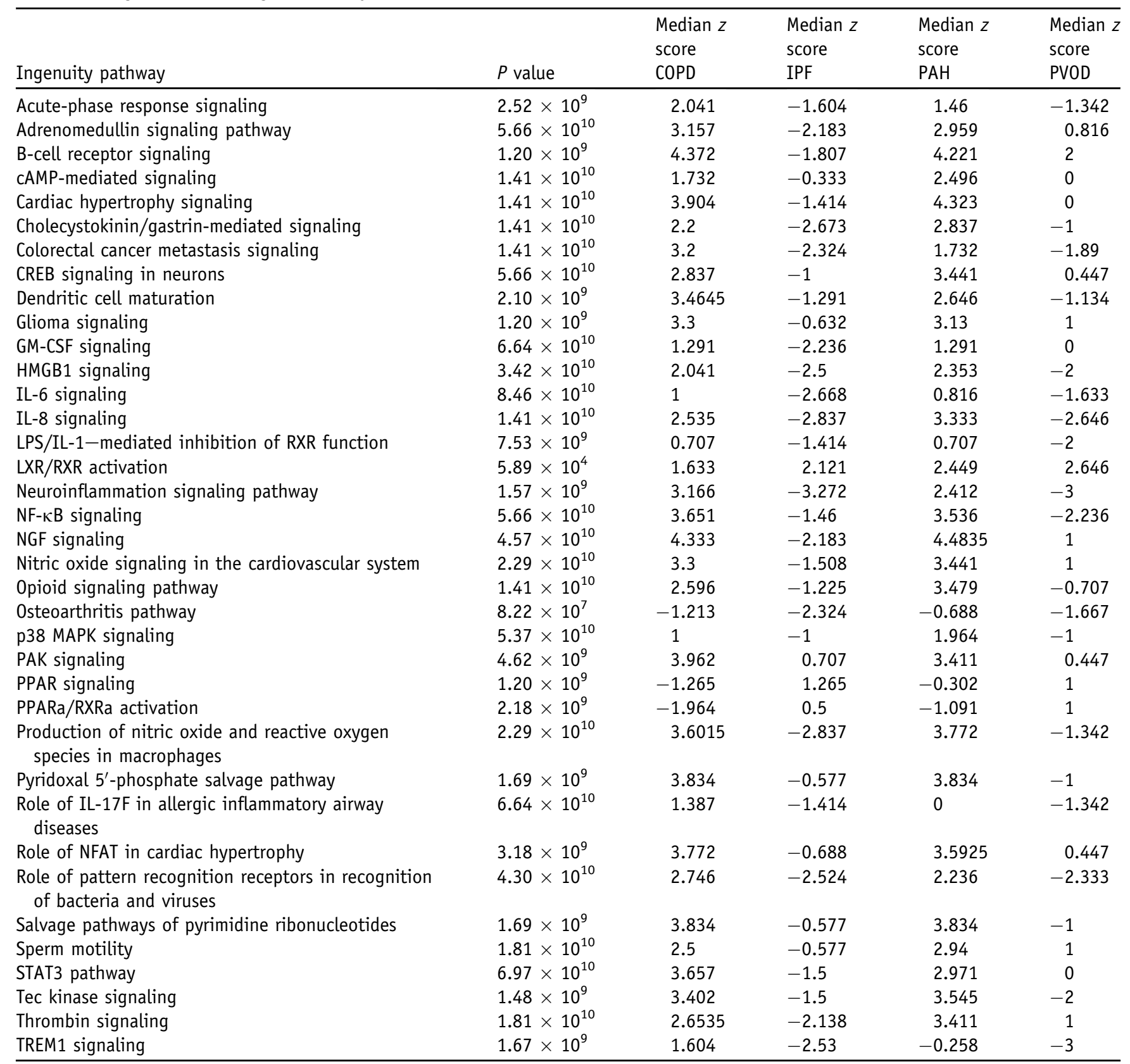

Regulation of biological pathways in chronic obstructive pulmonary disease (COPD), idiopathic pulmonary fibrosis (IPF), pulmonary arterial hypertension (PAH), and pulmonary veno-occlusive disease (PVOD) compared with control samples predicted by Ingenuity Pathway Analysis. Positive median $z$ scores indicate an up-regulation and negative scores a down-regulation of pathways. $P$ values have been calculated via Kruskal-Wallis tests.

CREB, CAMP response binding element-binding protein; GM-CSF, granulocyte-macrophage colony-stimulating factor; HMGB1, high-mobility-group-protein B1; LPS, ipopolysaccharid; LXR, liver $X$ receptor; MAPK, mitogen-activated protein kinases; NFAT, nuclear factor of activated T cells; NF- $K B$, nuclear factor kappa-light-chain-enhancer of activated B cells; NGF, nerve growth factor; PAK, p21-activated kinase; PPAR, peroxisome proliferator-activated receptor; RXR, retiniod $X$ receptor; STAT3, signal transducer and activator of transcription 3; TREM1, triggering receptor expressed on myeloid cells 1.

decreased cell viability and cell survival in PAH (Figure 6). Conversely, the pulmonary environment in IPF and PVOD appeared antiapoptotic, antinecrotic, and anti-inflammatory, with decreased migration of leukocytes. Moreover, IPF exhibited characteristics of increased proliferation of lymphocytes and characteristics of viral infection (Figure 6).
IPA was not able to generate $z$ scores for the prediction of diseases and functions in COPD.

Bonferroni multiple comparison tests of multiplex immunohistochemistry data revealed a decreased protein expression of ABL proto-oncogene 2 (ABL2) in COPD and an increased expression in PAH and IPF compared with 


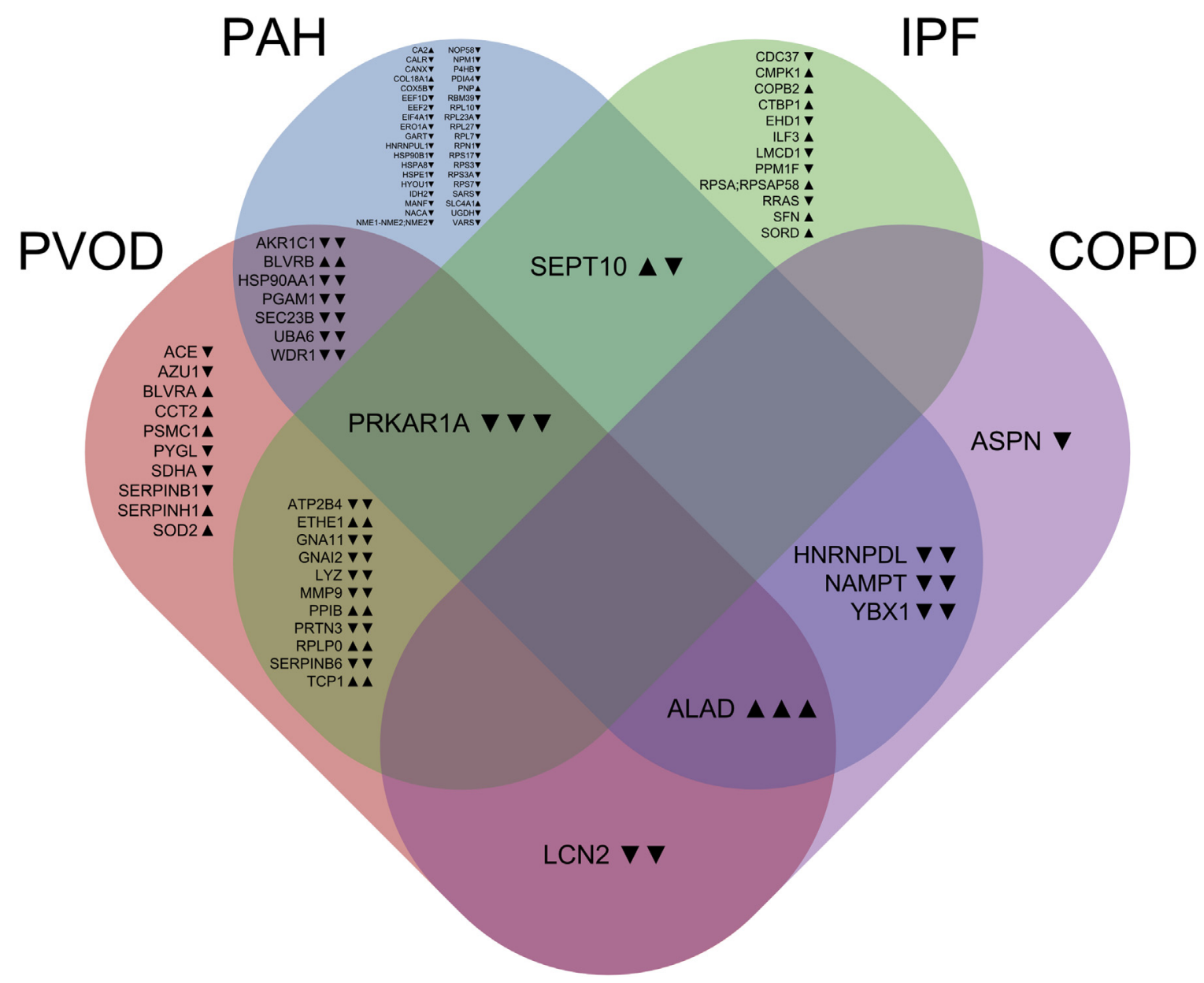

Figure 5 Venn diagram of differentially regulated proteins in chronic obstructive pulmonary disease (COPD), idiopathic pulmonary fibrosis (IPF), pulmonary arterial hypertension (PAH), and pulmonary veno-occlusive disease (PVOD) compared with control samples. The up-regulation and down-regulation of significantly differentially expressed proteins are indicated by arrowheads (up arrowheads and down arrowheads, respectively). In intersection areas of two or more entities, arrowheads are representative for a single entity each and ordered accordingly: PVOD > PAH > IPF > COPD.

control (Supplemental Figure S2). SGK196 appeared decreased in COPD, PAH, and IPF, whereas C-C chemokine receptor type 7 (CCR7) appeared decreased in $\mathrm{PAH}$, IPF, and PVOD compared with control. FGR and transforming growth factor beta (TGF- $\beta$ ) were decreased in all entities compared with control. In contrast, MAST2 increased in all representatively stained entities compared with the control (Figure 7 and Supplemental Figure S2).

\section{Discussion}

This study investigated the shared and differential molecular characteristics of PH. In particular, the goal was to create a model with the power to differentiate between PAH and PVOD. We were able to generate a neuronal network that differentiated PVOD from PAH samples with a sensitivity of $100 \%$ and a specificity of $92 \%$ in a randomly chosen validation set. Moreover, close functional similarities were found between PVOD and IPF as well as between PAH and COPD.
A fundamental finding of this study was the increased expression of SGK196 and MAST2 in all examined patient groups, suggesting that both kinases play a key role in the formation of pulmonary vascular lesions. MAST2, alias MTSSK or MAST205, has been described as forming complexes with the cell-cell adhesion molecule protocadherin LKC. ${ }^{22}$ Protocadherin LKC and MAST2 are known to influence the contact inhibition in liver, kidney, and colon cancer. Apart from this action, SKG196 is a glycosylation-specific O-mannose kinase, which is involved in dystroglycan receptor function. ${ }^{23}$ Dystroglycans are adhesion molecules that provide cellular adhesion of endothelial cells to the extracellular matrix. ${ }^{24}$ Due to this property, dystroglycans promote vascular remodeling, as well as survival and migration of endothelial cells. Moreover, alterations of SGK196 are associated with congenital muscular dystrophy. ${ }^{23}$

Regarding the molecular differences between PVOD and $\mathrm{PAH}$, the decreased mRNA and protein expression of $M M P 9$ in human PVOD lung explants suggests a role of MMP9 in the remodeling of pulmonary veins and venules. 


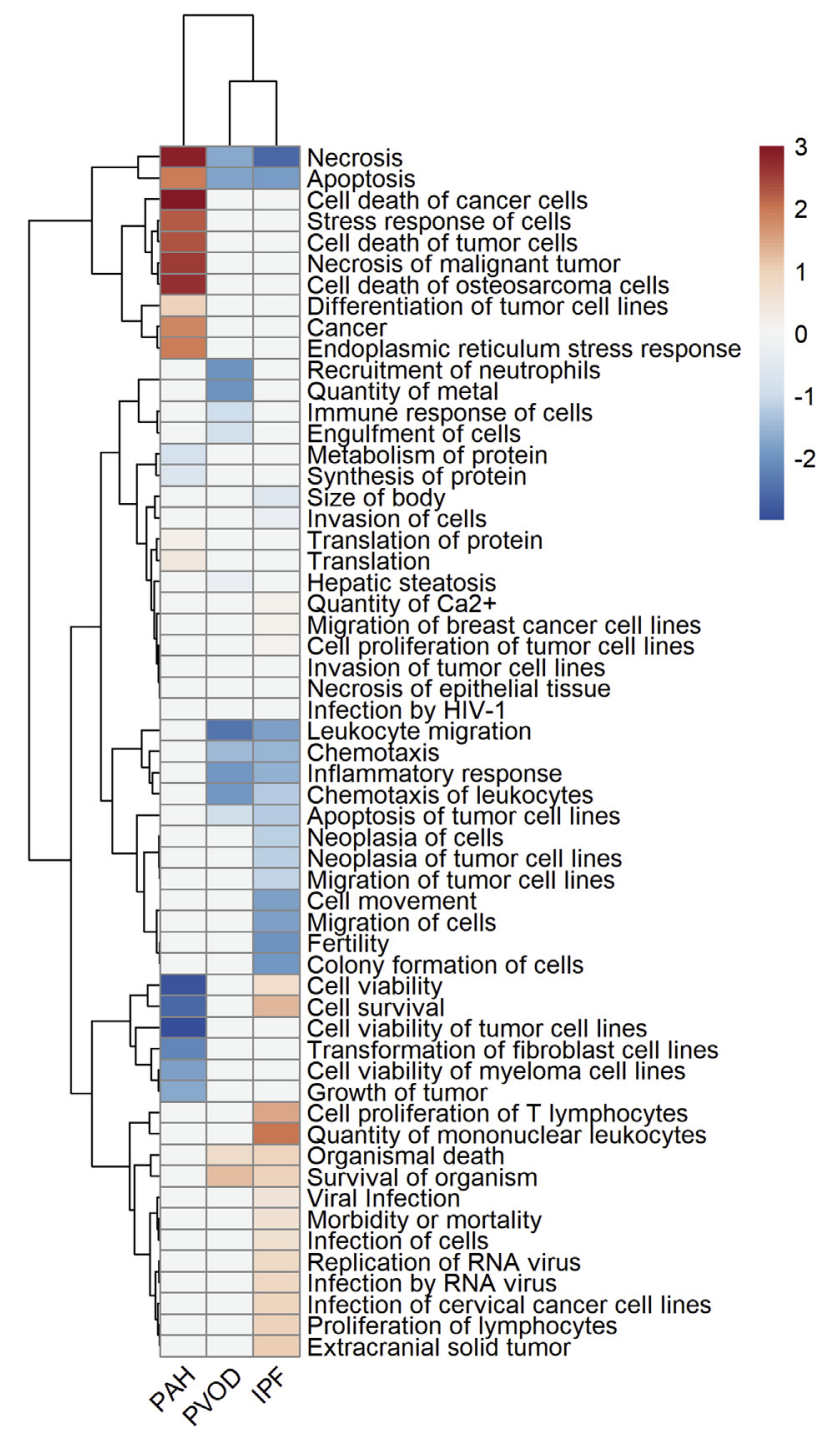

Figure 6 The heatmap shows the $z$ scores, predicting for the inactivation or activation of diseases and functions in pulmonary arterial hypertension (PAH), pulmonary veno-occlusive disease (PVOD), and idiopathic pulmonary fibrosis (IPF), conducted by using the Ingenuity Pathway Analysis. This analysis was not able to generate $z$ scores for the prediction of diseases and functions in chronic obstructive pulmonary disease.

MMP9 belongs to the family of matrix metalloproteinases (MMPs), pivotal enzymes for extracellular matrix modification and degradation in human lungs. ${ }^{25}$ It is known that dysregulation of MMPs is associated with obliterative vascular remodeling in $\mathrm{PH}$, which suggests that decreased $M M P 9$ in PVOD results in decreased vascular collagenolytic activity and thereby facilitates extracellular matrix deposition, a key element of PH. In fact, venous intima fibrosis and venous intraluminal septa and/or recanalization, the most common histopathologic alterations of PVOD, are likely a result of dysregulated collagenolysis. ${ }^{19,26}$ Focusing on the compartment-specific expression of MMP9 using immunohistochemistry, high MMP9 levels were observed on intravascular and perivascular lymphocytes in healthy human lung tissue, whereas these cells were rarely found in PVOD and IPF lung tissue (Figure 8). An intriguing finding by Day et $\mathrm{al}^{27}$ was the observation of urinary MMPs in two children with PVOD. Both PVOD and PAH showed a decreased expression of interleukin 10 (IL10). IL-10 is an anti-inflammatory cytokine, which is being discussed as mediating compensatory effects in idiopathic PAH and familial PAH by antagonizing the effects of pro-inflammatory cytokines such as IL-6 and IL-8. ${ }^{28}$ Paradoxically, serum levels of IL-10 are increased in patients with PAH and correlate inversely with survival. These differences between the local pulmonary and the systemic cytokine milieu suggest that increased serum levels of cytokines in patients with PAH might not originate from the lung but rather represent immunologic mechanisms of the systemic circulation.

Concerning the common features of PVOD and IPF, IPA labeled antiangiogenic, antichemotactic, antivasculogenic, antichemotactic, anti-inflammatory, and antimitogenic functional activity for both diseases, particularly seen by the decreased expression of CXCR1, C-X-C motif chemokine receptor 2 (CXCR2), FGR, and interleukin 18 receptor accessory protein receptor $(I L-18 R A P)$. FGR is a member of the Src family of tyrosine kinases regulating cellular adhesion, migration, apoptosis, and differentiation. ${ }^{29}$ Src kinases are also involved in the downstream regulation of profibrotic cytokines in IPF, as transforming growth factor beta (TGF- $\beta$ ) or platelet-derived growth factor. ${ }^{30}$ Moreover, interleukin 18 receptor accessory protein (IL-18RAP) is a subunit of the heterodimeric receptor for IL-18, which is an indispensable proinflammatory cytokine for the acquired immune system defending against viruses, bacteria, and parasites. ${ }^{31}$ Here, the decreased expression of $I L-18 R A P$ and $F G R$ indicate an exaggerated anti-inflammatory or rather an excessive wound-healing reaction. Furthermore, the hypothesis of a disturbed wound-healing reaction is also supported by the decreased expression of $C X C R 1$ and $C X C R 2$. Both CXCR1 and CXCR2 are chemokine receptors of the neutrophil-activating peptide IL-8, and a decreased expression is therefore obviously associated with impaired neutrophilic chemotaxis and decreased neutrophilic tissue influx. ${ }^{32}$ In this regard, the functional presentation on the protein level of an antiapoptotic, antinecrotic, and antiinflammatory pulmonary environment in PVOD and IPF substantially differs from the functional presentation in PAH. Furthermore, the hypothesis of decreased leukocyte migration in PVOD is also supported by IPA functional analysis (Figure 6). Neutrophils represent important immune cells for healing responses by promoting revascularization and tissue repair through the expression of MMP9. ${ }^{33} \mathrm{An}$ insufficient neutrophilic recruitment might therefore contribute to fibrous venous occlusions. These observations prompt us to assume that IPF and PVOD share significant traits in vascular pathophysiology. Indeed, when considering morphologic similarities, occlusive venopathy has been described as a common phenomenon of remodeling in IPF. $^{34}$ Otherwise, interstitial fibrosis, a morphologic 


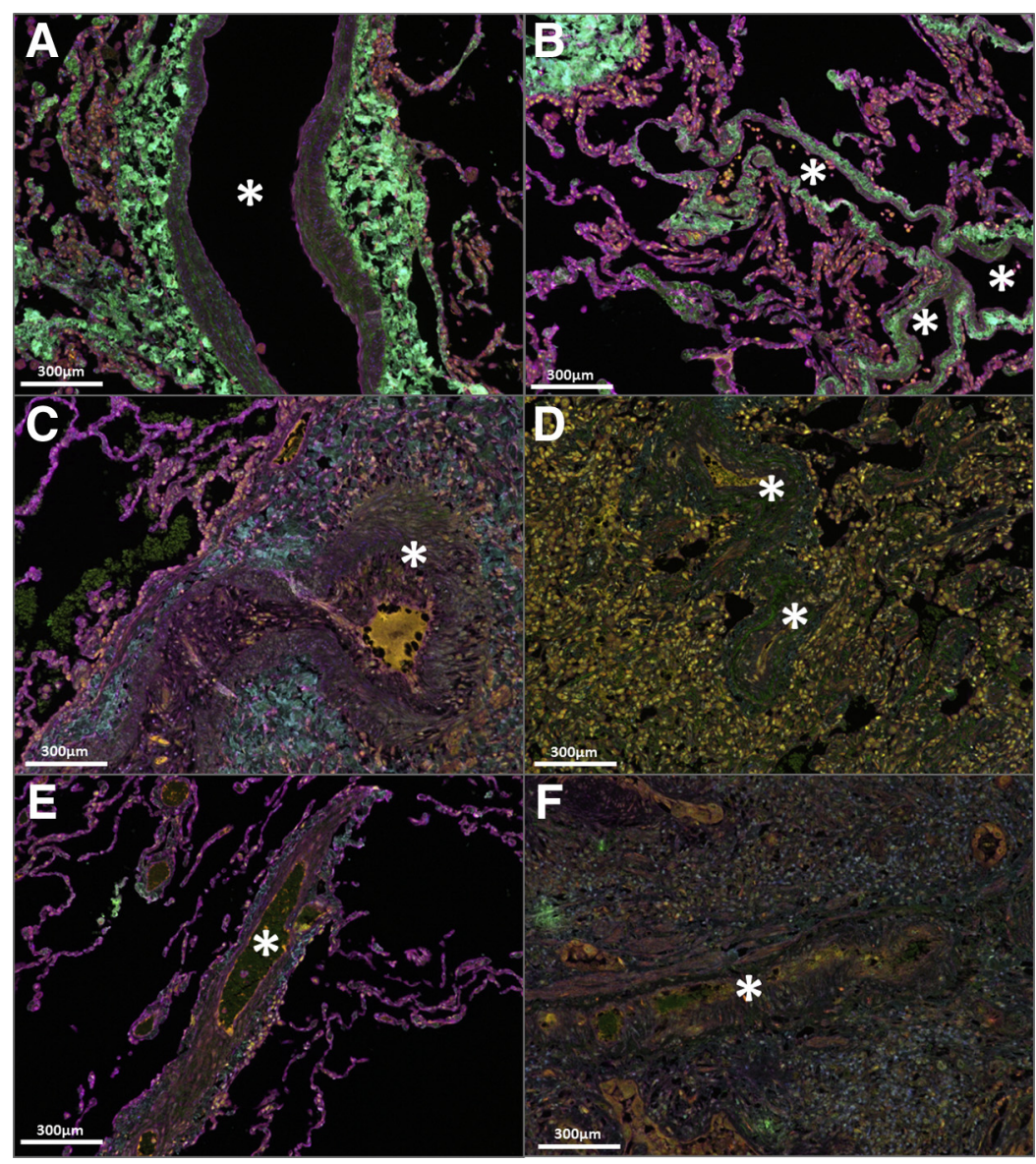

Figure 7 Multiplex immunohistochemical staining showing C-C chemokine receptor 7 (CCR7) in magenta, transforming growth factor- $\beta$ in green, Gardner-Rasheed feline sarcoma viral oncogene in red, $A B L$ protooncogene 2 in cyan, protein 0-mannose kinase SGK196 in orange, and microtubule-associated serine/threonine kinase 2 in yellow. A: Physiologic pulmonary artery (asterisk) in a healthy human control lung. B: Physiologic pulmonary veins (asterisks) in a healthy human control lung. C: Remodeled pulmonary artery (asterisk) in pulmonary arterial hypertension. D: Remodeled pulmonary veins (asterisks) in pulmonary veno-occlusive disease. E: Remodeled pulmonary artery (asterisk) in chronic obstructive pulmonary disease. F: Remodeled pulmonary artery (asterisk) in idiopathic pulmonary fibrosis. Scale bars $=300 \mu \mathrm{m}(\mathbf{A}-\mathbf{F})$.

hallmark of IPF, is also a frequently observed alteration in PVOD lungs. ${ }^{19}$

Conversely, according to this functional analysis, PAH and COPD are proinflammatory, proangiogenic, provasculogenic, and prochemotactic for immune cells and promitogenic with increased DNA transcription and increased protein kinase activity. Pro-inflammatory cytokines in the blood of patients with PAH have been described as a key hallmark of pulmonary inflammation. ${ }^{28}$ Interestingly, in addition to a local proinflammatory pulmonary microenvironment characterized by chronic bronchitis, obstructive bronchiolitis, and progressive emphysema, systemic inflammation is associated with pulmonary hypertension in COPD. ${ }^{21,35}$ These findings of a proinflammatory and proproliferative pulmonary milieu in PAH are also supported by recently discovered immunoglobulin-driven processes in $\mathrm{PAH}$, as described by Frid et al. ${ }^{36}$ In summary, the molecular mechanisms of postcapillary and precapillary pulmonary vascular remodeling show substantial differences, whereas their impact on the clinical outcome of $\mathrm{PH}$ patients remains poorly understood.

This study is the first to put forward a molecular model with the ability to differentiate between patients with $\mathrm{PH}$ due to predominantly precapillary pulmonary vascular remodeling (PAH) and PVOD lung explants with predominantly postcapillary pulmonary vascular remodeling. The model used 6 genes [CXCR1, serine/threonine kinase 4 (STK4), toll-like receptor 4 (TLR4), arginase 1 (ARG1), calcium/calmodulin dependet kinase II alpha chain $(C A M K 2 A)$, and ribosomal protein S6 kinase A5 (RPS6KA5)] and achieved an accuracy of $96 \%$ against a randomly chosen validation set. Considering the relatively large size of the validation set used in our study (60\% of the available data), we are confident that the achieved classification accuracy is close to the gold standard, histopathologic diagnosis; therefore, molecular discrimination of PAH and PVOD may indeed be feasible. Because lung biopsies, the gold standard for the diagnosis of PVOD, remain as highrisk interventions for patients with $\mathrm{PH}$, and noninvasive approaches currently do not lead to high diagnostic accuracy, these findings may open a concept facilitating diagnostics of PVOD by molecular analysis, provided that these findings are reproducible in blood or urine samples. ${ }^{37}$

However, some limitations should be discussed. First, the number of 19 PVOD cases in this study is relatively low, although it has to be noted that PVOD represents a very rare and often misdiagnosed entity, even among patients with $\mathrm{PH}$, and that fresh lung explants worked up in a standardized and comprehensive manner from a single center are not nearly as small of a study collective. 


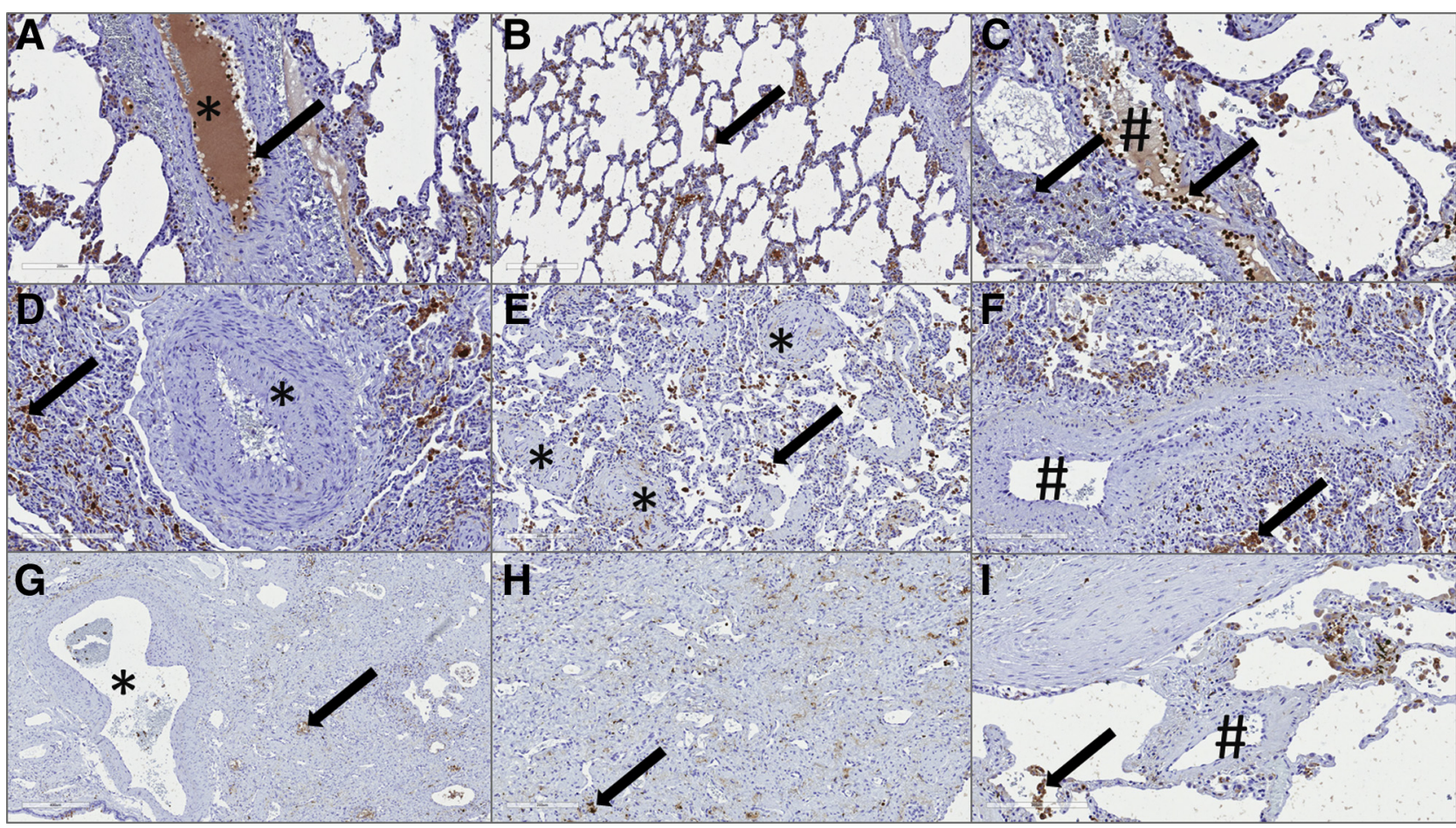

Figure 8 Immunohistochemical staining using an anti-matrix metalloproteinase 9 (MMP9) antibody on human lung explant tissue. A: Healthy control showing MMP-9-positive lymphocytes (arrow) in a pulmonary artery (asterisk). B and C: MMP-9-positive lymphocytes (arrows in C) are shown in and next to a pulmonary vein (hash mark) and MMP-9-positive macrophages in the alveolar spaces (arrow in B). D-F: Pulmonary veno-occlusive disease showing MMP9-positive alveolar macrophages (arrow in $\mathbf{D}$ ) next to a remodeled pulmonary artery (asterisk in D), MMP-9-positive alveolar macrophages (arrow in $\mathbf{E}$ ) next to remodeled small pulmonary veins (asterisks in E), and MMP-9-positive alveolar macrophages (arrow in $\mathbf{F}$ ) next to a remodeled large pulmonary vein (hash mark in F). G-I: Idiopathic pulmonary fibrosis showing weakly MMP-9-positive alveolar macrophages (arrow in G) next to a pulmonary artery (asterisk in G), MMP-9-positive alveolar macrophages (arrow in $\mathbf{H}$ ) within the fibrotic lung tissue (H), and MMP-9-positive alveolar macrophages (arrow in $\mathbf{I}$ ) next to a pulmonary vein (hash mark in I). Scale bars: $200 \mu \mathrm{m}(\mathbf{A}, \mathbf{C}, \mathbf{D}, \mathbf{E}, \mathbf{F}, \mathbf{H}$, and I); $300 \mu \mathrm{m}(\mathbf{B}) ; 400 \mu \mathrm{m}$ (G).

To compensate for the sizes of the patient groups, every lung was sampled extensively, and every anatomic compartment was examined. Of these locations, the morphologically most representative areas, according to the criteria of the respective international guidelines, were selected for further analysis; however, differences within individual patients were not analyzed. Because one of the cornerstones of this study was to only include clinically and morphologically well-characterized patients/tissue specimens, we deliberately chose to only include lung explants worked up according to our high standards. These findings have yet to be confirmed in a separate validation cohort. In this regard, close cooperation between different transplantation centers would allow the enlargement of study groups and additional validation of our model in further studies. Nevertheless, compared with a whole transcriptome microarray analysis of $58 \mathrm{PAH}$ and 25 control lungs by Stearman et al, ${ }^{38}$ this study yields a similar set of significantly regulated genes between these two groups, with near-complete identical patterns of up-regulation and downregulation (only considering genes used in this study; data not shown). Second, these findings actually are restricted to the pulmonary environment; the robustness of this approach must be investigated on additional and more easily available biomaterials (eg, using circulatory RNAs in blood and urine samples). Third, these findings in end-stage disease have to be correlated with the clinical course of disease, using tissue specimens sampled at an earlier stage of progression, to enable a differentiation between PAH and PVOD as early as possible. However, given the often obscure and misleading clinical presentation of PVOD, and the contraindications for obtaining lung biopsy samples, the disease is often only diagnosed in the lung explants after transplantation. In this regard, novel nonintubated and uniportal video-assisted thoracoscopic surgery lung biopsies have been shown to be a safe diagnostic procedure in patients with pulmonary capillary hemangiomatosis and could therefore represent a new tool for early diagnostics of PVOD. ${ }^{39}$ Moreover, although the patients are indeed end-stage at the time of transplantation, the spatial and temporally heterogeneous vascular remodeling found in explanted PVOD lungs strongly suggests that the disease mechanisms are indeed not.

In conclusion, we present the first study to differentiate between human PVOD and PAH by gene expression analysis with a high accuracy of $96 \%$ against a randomly chosen validation cohort. Surprisingly, PVOD shared more characteristics with IPF than with PAH. We also identified a large number of dysregulated genes on mRNA and protein levels in lung explants from patients with severe pulmonary 
vascular remodeling regardless of the afflicted compartments. MMP9 signaling in PVOD and MAST2 and SGK196 signaling in various forms of severe $\mathrm{PH}$ might serve as novel pharmaceutical targets with the potential to address severe vascular remodeling. Further studies are required to investigate the diagnostic value of the identified markers in the clinical setting.

\section{Acknowledgments}

We thank Annette Mueller-Brechlin, Valery Volk, and Nicole Krönke for their excellent technical support; and Kara Diemer, Gareth Griffiths, and Jill Barry for critical reading of the manuscript.

\section{Author Contributions}

L.N., P.B., M.K., and D.J. designed the study, acquired and interpreted data, and wrote and revised the manuscript; H.S., A.H., and H.-H.K. interpreted data and wrote the manuscript; J.V.-C., G.W., and M.M.H. provided clinical data and revised the manuscript; H.E. and P.K. acquired data and revised the manuscript; all authors approved the final version of the manuscript for publishing.

\section{Supplemental Data}

Supplemental material for this article can be found at http://doi.org/10.1016/j.ajpath.2020.03.008.

\section{References}

1. Galiè N, Humbert M, Vachiery JL, Gibbs S, Lang I, Torbicki A, Simonneau G, Peacock A, Vonk Noordegraaf A, Beghetti M, Ghofrani A, Gomez Sanchez MA, Hansmann G, Klepetko W, Lancellotti P, Matucci M, McDonagh T, Pierard LA, Trindade PT, Zompatori M, Hoeper M: 2015 ESC/ERS guidelines for the diagnosis and treatment of pulmonary hypertension: The Joint Task Force for the Diagnosis and Treatment of Pulmonary Hypertension of the European Society of Cardiology (ESC) and the European Respiratory Society (ERS): Endorsed by: Association for European Paediatric and Congenital Cardiology (AEPC), International Society for Heart and Lung Transplantation (ISHLT). Eur Heart J 2016, 37:67-119

2. Simonneau G, Montani D, Celermajer D, Denton C, Gatzoulis M, Krowka M, Williams P, Souza R: Haemodynamic definitions and updated clinical classification of pulmonary hypertension. Eur Respir J 2019, 53:1801913

3. Montani D, O' Callaghan DS, Savale L, Jas X, Yaci A, Maitre S, Dorfmuller P, Sitbon O, Simonneau G, Humbert M: Pulmonary venoocclusive disease: recent progress and current challenges. Respir Med 2010, 104 Suppl 1:S23-S32

4. Montani D, Girerd B, Jaïs X, Levy M, Amar D, Savale L, Dorfmüller P, Seferian A, Lau EM, Eyries M, Le Pavec J, Parent F, Bonnet D, Soubrier F, Fadel E, Sitbon O, Simonneau G, Humbert M: Clinical phenotypes and outcomes of heritable and sporadic pulmonary veno-occlusive disease: a population-based study. Lancet Respir Med 2017, 5:125-134

5. Ogawa A, Sakao S, Tanabe N, Matsubara H, Tatsumi K: Use of vasodilators for the treatment of pulmonary veno-occlusive disease and pulmonary capillary hemangiomatosis: a systematic review. Respir Investig 2019, 57:183-190

6. Montani D, Achouh L, Dorfmüller P, Le Pavec J, Sztrymf B, Tchérakian C, Rabiller A, Haque R, Sitbon O, Jaïs X, Dartevelle P, Maître S, Capron F, Musset D, Simonneau G, Humbert M: Pulmonary veno-occlusive disease: clinical, functional, radiologic, and hemodynamic characteristics and outcome of 24 cases confirmed by histology. Medicine (Baltimore) 2008, 87:220-233

7. Seeger W, Adir Y, Barberà JA, Champion H, Coghlan JG, Cottin V, De Marco T, Ghio S, Gibbs S, Martinez FJ, Semigran MJ, Wells AU, Vachiéry JL: Pulmonary hypertension in chronic lung diseases. J Am Coll Cardiol 2013, 62 Suppl 25:D109-D116

8. Hassoun PM, Mouthon L, Barberà JA, Eddahibi S, Flores SC, Grimminger F, Jones PL, Maitland ML, Michelakis ED, Morrell NW, Newman JH, Rabinovitch M, Schermuly R, Stenmark KR, Voelkel NF, Yuan JX- J, Humbert M: Inflammation, growth factors, and pulmonary vascular remodeling. J Am Coll Cardiol 2009, 54 Suppl 1:S10-S19

9. Dorfmüller P, Perros F, Balabanian K, Humbert M: Inflammation in pulmonary arterial hypertension. Eur Respir J 2003, 22:358-363

10. Länger F, Stark H, Braubach P, Ackermann M, Hussein K, Teiken K, Maegel L, Kuehnel M, Jonigk D: [Injury patterns in interstitial lung diseases] German. Pathologe 2018, 39:262-271

11. Geiss GK, Bumgarner RE, Birditt B, Dahl T, Dowidar N, Dunaway DL, Fell HP, Ferree S, George RD, Grogan T, James JJ, Maysuria M, Mitton JD, Oliveri P, Osborn JL, Peng T, Ratcliffe AL, Webster PJ, Davidson EH, Hood L: Direct multiplexed measurement of gene expression with color-coded probe pairs. Nat Biotechnol 2008, 26:317-325

12. R Core Team: R: a language and environment for statistical computing. Vienna, Austria: R Foundation for Statistical Computing, 2018

13. Krämer A, Green J, Pollard J, Tugendreich S: Causal analysis approaches in ingenuity pathway analysis. Bioinformatics 2014, 30: $523-530$

14. Thal B, Braun HP, Eubel H: Proteomic analysis dissects the impact of nodulation and biological nitrogen fixation on Vicia faba root nodule physiology. Plant Mol Biol 2018, 97:233-251

15. Fromm S, Senkler J, Eubel H, Peterhänsel C, Braun HP: Life without complex I: proteome analyses of an Arabidopsis mutant lacking the mitochondrial NADH dehydrogenase complex. J Exp Bot 2016, 67: 3079-3093

16. Cox J, Mann M: MaxQuant enables high peptide identification rates, individualized p.p.b.-range mass accuracies and proteome-wide protein quantification. Nat Biotechnol 2008, 26:1367-1372

17. Mascaux C, Angelova M, Vasaturo A, Beane J, Hijazi K, Anthoine G, Buttard B, Rothe F, Willard-Gallo K, Haller A, Ninane V, Burny A, Sculier JP, Spira A, Galon J: Immune evasion before tumour invasion in early lung squamous carcinogenesis. Nature 2019, 571:570-575

18. Heath D, Edwards JE: The pathology of hypertensive pulmonary vascular disease; a description of six grades of structural changes in the pulmonary arteries with special reference to congenital cardiac septal defects. Circulation 1958, 18:533-547

19. Lantuéjoul S, Sheppard MN, Corrin B, Burke MM, Nicholson AG: Pulmonary veno-occlusive disease and pulmonary capillary hemangiomatosis a clinicopathologic study of 35 cases. Am J Surg Pathol 2006, 30:850-857

20. Katzenstein A, Myers JL: Idiopathic pulmonary fibrosis clinical relevance of pathologic classification clinical features of the idiopathic interstitial pneumonias. Am J Respir Crit Care Med 1998, 157:1301-1315

21. Hogg JC, Timens W: The pathology of chronic obstructive pulmonary disease. Annu Rev Pathol 2009, 4:435-459

22. Okazaki N, Takahashi N, Kojima S, Masuho Y, Koga H: Protocadherin LKC, a new candidate for a tumor suppressor of colon and liver cancers, its association with contact inhibition of cell proliferation. Carcinogenesis 2002, 23:1139-1148 
23. Yoshida-Moriguchi $\mathrm{T}$, Willer $\mathrm{T}$, Anderson ME, Venzke $\mathrm{D}$, Muntoni F, Lee H, Nelson SF, Yu L, Kevin P: SGK196 is a glycosylation-specific O-mannose kinase required for dystroglycan function. Science 2013, 341:896-899

24. Galvagni F, Nardi F, Maida M, Bernardini G, Vannuccini S, Petraglia F, Santucci A, Orlandini M: CD93 and dystroglycan cooperation in human endothelial cell adhesion and migration. Oncotarget 2016, 7:10090-10103

25. Chelladurai P, Seeger W, Pullamsetti SS: Matrix metalloproteinases and their inhibitors in pulmonary hypertension. Eur Respir J 2012, 40:766-782

26. Wagenvoort CA, Wagenvoort N, Takahashi T: Pulmonary venoocclusive disease: involvement of pulmonary arteries and review of the literature. Hum Pathol 1985, 16:1033-1041

27. Day RW, Clement PW, Hersh AO, Connors SM, Sumner KL, Best DH, Alashari M: Pulmonary veno-occlusive disease: two children with gradual disease progression. Respir Med Case Rep 2017, 20:82-86

28. Soon E, Holmes AM, Treacy CM, Doughty NJ, Southgate L, MacHado RD, Trembath RC, Jennings S, Barker L, Nicklin P, Walker C, Budd DC, Pepke-Zaba J, Morrell NW: Elevated levels of inflammatory cytokines predict survival in idiopathic and familial pulmonary arterial hypertension. Circulation 2010, 122:920-927

29. Tatosyan AG, Mizenina OA: Kinases of the Src family: structure and functions. Biochemistry (Mosc) 2000, 65:49-58

30. Beyer C, Distler JH: Tyrosine kinase signaling in fibrotic disorders: translation of basic research to human disease. Biochim Biophys Acta 2013, 1832:897-904

31. Yasuda K, Nakanishi K, Tsutsui H: Interleukin-18 in health and disease. Int J Mol Sci 2019, 20:649
32. Hébert CA, Baker JB: Interleukin-8: a review. Cancer Invest 1993, $11: 743-750$

33. Kolaczkowska E, Kubes P: Neutrophil recruitment and function in health and inflammation. Nat Rev Immunol 2013, 13:159-175

34. Colombat M, Mal H, Groussard O, Capron F, Thabut G, Jebrak G, Brugière $\mathrm{O}$, Dauriat $\mathrm{G}$, Castier $\mathrm{Y}$, Lesèche $\mathrm{G}$, Fournier M: Pulmonary vascular lesions in end-stage idiopathic pulmonary fibrosis: histopathologic study on lung explant specimens and correlations with pulmonary hemodynamics. Hum Pathol 2007, 38:60-65

35. Joppa P, Petrasova D, Stancak B, Tkacova R: Systemic inflammation in patients with COPD and pulmonary hypertension. Chest 2006, 130:326-333

36. Frid MG, McKeon BA, Thurman JM, Maron BA, Li M, Zhang H, Kumar S, Sullivan T, Laskowsky J, Fini MA, Hu S, Tuder RM, Gandjeva A, Wilkins MR, Rhodes CJ, Ghataorhe P, Leopold JA, Wang RS, Michael Holers V, Stenmark KR: Immunoglobulin-driven complement activation regulates proinflammatory remodeling in pulmonary hypertension. Am J Respir Crit Care Med 2020, 201: 224-239

37. Montani D, Price LC, Dorfmuller P, Achouh L, Jaïs X, Yaïci A, Sitbon O, Musset D, Simonneau G, Humbert M: Pulmonary venoocclusive disease. Eur Respir J 2009, 33:189-200

38. Stearman RS, Bui QM, Speyer G, Handen A, Cornelius AR, Graham BB, Seungchan K, Mickler EA, Tuder RM, Chan SY, Geraci MW: Systems analysis of the human pulmonary arterial hypertension lung transcriptome. Am J Respir Cell Mol Biol 2019, 60:637-649

39. Liu M, Cui W, Peng G, Xu X: Novel lung biopsy surgical technique for definitive diagnosis of pulmonary capillary hemangiomatosis. Ann Thorac Surg 2020, 109:291-293 